\title{
Evaluation of beach nourishment works on Miyazaki coast in Japan
}

\author{
Keisuke Murakami ${ }^{1 *}$, and Khusnul Setia Wardani ${ }^{2}$ \\ ${ }^{1}$ International Education Center, University of Miyazaki, Japan \\ ${ }^{2}$ Department of Interdisciplinary Graduate School of Agriculture and Engineering, University of \\ Miyazaki, Japan
}

\begin{abstract}
Miyazaki Coast have been suffering from severe erosion problem due to the shortage of sediment supply from rivers and the change of waves and nearshore currents by the construction of an offshore breakwater at Miyazaki Port. In order to reproduce a wide sandy beach, a beach nourishment project has been done since 2008 in combination with the installation of Sand-Packed containers that were placed in front of dune. A certain volume of nourishment sand has been installed for the sand fill works that cover Sand-Packed containers, and the rest has been dumped off the coast. The purpose of this research is to evaluate the effectiveness of beach nourishment works with using long-term bottom sounding data. This study discussed the effect of the beach nourishment on longshore sandbar evolution. The change of the sand volume in research area was also discussed in this study.
\end{abstract}

\section{Introduction}

Miyazaki Coast is located on the eastern side of Kyushu Island in Japan, and it faces the Pacific Ocean. As shown in Fig. 1, this coast extends from Miyazaki Port to the Mimi River mouth. Some rivers flow into this coast and supply sediments. Miyazaki Coast has been suffering from a beach erosion due to the shortage of the sediment supply from those rivers and also the change of waves and nearshore currents by the construction of an offshore breakwater at Miyazaki Port $[1,2]$. The shortage of sand supply from rivers in the coastal area sometimes affects the formation of a longshore sandbar [3]. Notably, the disappearance of the longshore sandbar accelerates the beach erosion. Takano et al. [4] investigated the relationship between the disappearance of the longshore sandbar and the beach erosion on Miyazaki Coast.

Some countermeasures such as detached breakwaters, seawalls, and gentle slope revetments have been implemented to control shoreline recession. Although these structures have been protecting a land behind the coast, these could not reproduce a wide sandy beach. New strategies have been applied to some beaches on this coast to reproduce the sandy beach with a certain width. One is the Sand-Packed containers in Fig. 2 (a) as a short-term measure [5]. Others are the construction of some jetties as a middle-term measure and the

\footnotetext{
* Corresponding author: keisuke@,cc.miyazaki-u.ac.jp
} 
complete sediment control on the watershed area of main rivers as a long-term measure. A beach nourishment project on Miyazaki Coast was employed to supplement the comprehensive sediment control since 2008.

\section{Methodology}

This study evaluates the effectiveness of the beach nourishment implemented on Miyazaki Coast using long-term bottom sounding data. After that, this study discusses the effect of the beach nourishment on longshore sandbar evolution. The change of the sand volume in the research area is also addressed in this study.

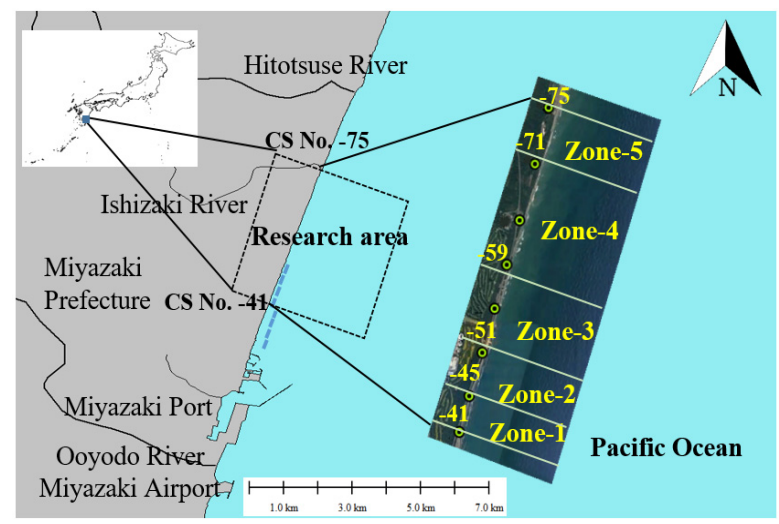

Fig. 1. Location of research area.

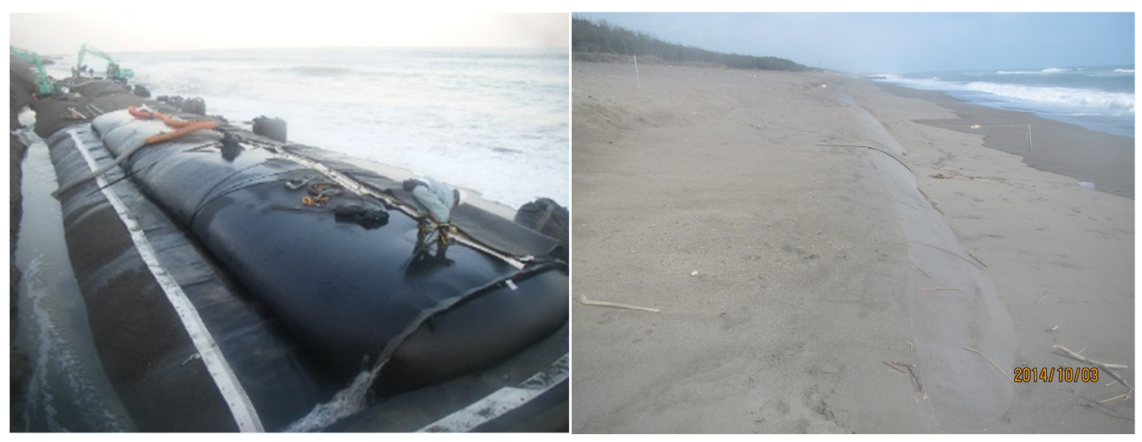

(a)

(b)

Fig. 2. Sand-packed containers (a) installation of containers, (b) containers covered with nourisment sand.

\section{Results and discussion}

\subsection{Outline of beach nourishment}

Fig. 3 shows the location of the beach nourishment which was conducted on Miyazaki coast. The beach nourishment has started since 2008. A specific volume of nourishment sand has been used for a sand fill work that covers the sand-packed containers placed in front of dunes (see Fig. 2(b)), and the rest has been dumped off the coast. 
Fig. 4 shows the volume of nourishment sand from 2008 to 2015. There are two primary sources for the nourishment works. One is the dredged sand in Miyazaki Port and other ports, and the other is the dredged sand from the Hitotsuse River and Ooyodo River. Large dredging works had been done along these rivers since 2004, and a specific volume of sand could be available. The sand volume varies year by year depending on the availability of sand. The total volume of the nourished sand for eight years was about $1,007,496 \mathrm{~m}^{3}$.

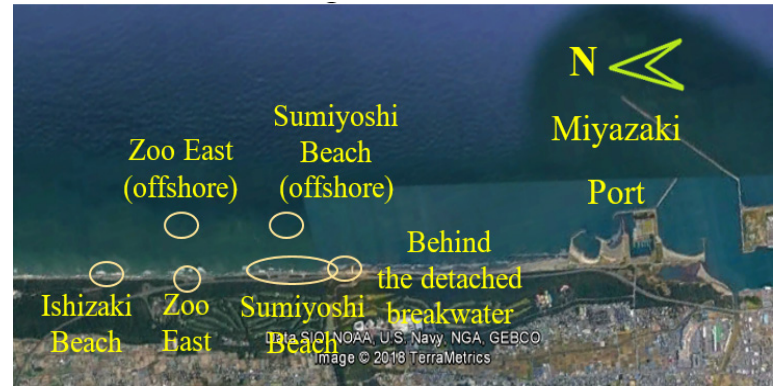

Fig. 3. Location of beach nourishment.

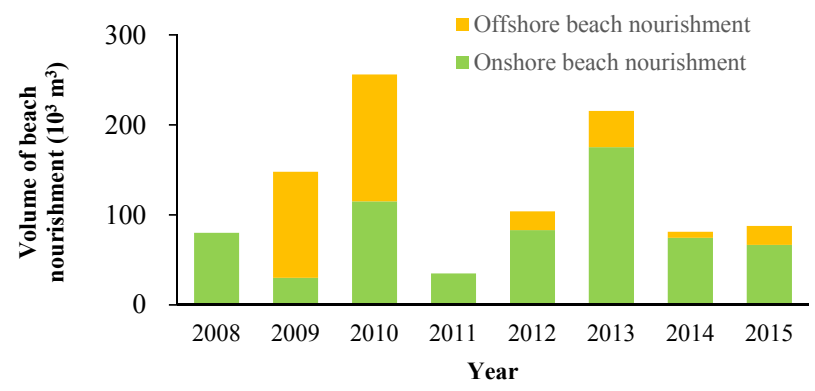

Fig. 4. Volume of beach nourishment.

\subsection{Change of sea bottom topography}

This study used the bottom sounding data, cross sections from No.-41 to No.-75 in Fig. 1. The data was taken from 1982 to 2015 . There are some detached breakwaters from No.-41 to No.-51. Gentle slope revetments and seawalls are also constructed between No.-51 to No.-62 and No.-72 to No.-74. Other areas remain as a natural beach.

Fig.5 shows some sea bottom profiles at No.-42. The notation of "Typhoon season" means the season from July to October, and "Gentle season" means the season from November to next June. The origin of the cross-shore distance is the base-point of each cross-section, as shown in Fig. 1. The migration of longshore sandbar can be observed in these profiles. The sea bottom profiles changed mostly year by year. This study calculates a standard deviation, $\mathrm{SD}$, to the change of the depth for several years along the cross sections, and characterizes the spacial topograph change on the research area.

Judging from the pattern of cross-shore distribution of SD, this study divided the research area into five subzones as shown in Fig. 1. From No.-41 to No.-45 is Zone-1, from No.-46 to No.-51 is Zone-2, from No.-52 to No.-59 is Zone-3, from No.-60 to No.-71 is Zone-4, and from No.-72 to No.-75 is Zone-5. Each zone shows the large number of SD in the shallow water area, the range from 0 to $200 \mathrm{~m}$. This range includes shoreline, and the topography changes seasonally depending on the wave actions. The number of SD also 
increases around 400-500 $\mathrm{m}$ from the base-point. Longshore sandbar migration sometimes occurs around here, and the disappearance or development of sandbars increases SD.

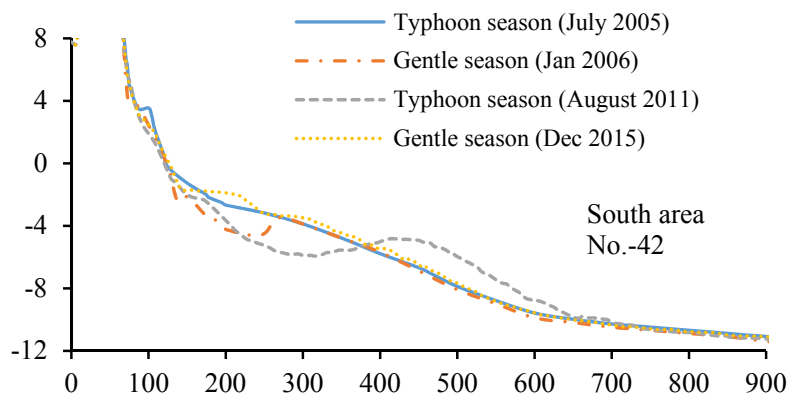

Fig. 5. Example of sea bottom profile change in research area.

\subsection{Sand volume change}

Sato et al. [6] and Sugiyama et al. [7] investigated the characteristics of long-term sediment transport in Miyazaki Coast. Higashi et al. [8] also studied sediment transport around the Hitotsuse River mouth based on Luminescence measurements. These researches showed that both southward and northward sediment transport occurs on Miyazaki Coast according to the season, and the southward sediment transport is dominant throughout a year.

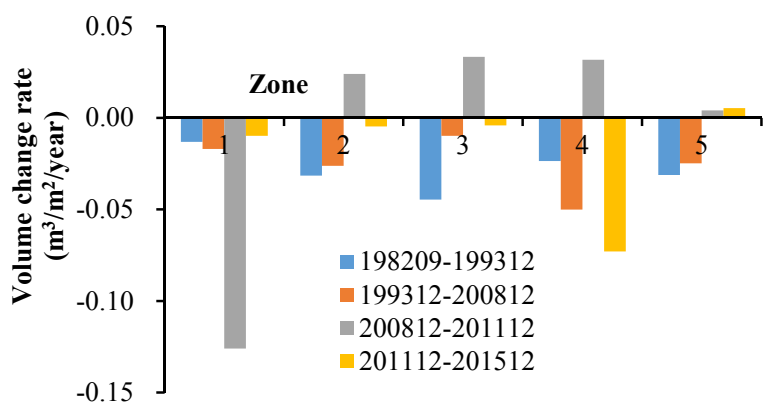

Fig. 6. Rate of sand volume change in each period.

Fig. 6 shows the rate of the sand volume change in each zone. The difference of the sand volume in each zone was calculated along the cross-section between $100 \mathrm{~m}$ from the base-point to $900 \mathrm{~m}$ offshore. The rate is a value per unit area in each zone. The trend of the rate differs before and after the implementation of beach nourishment. Some favorable rates can be seen in the period from 2008 to 2011 in Zone-2, 3, and Zone-4, and from 2008 to 2015 in Zone-5. The magnitude of the negative volume change in Zone-2, 3, and Zone-5 seems to decrease after the beach nourishment started. Zone-1 had a significant negative rate in the period from 2008 to 2011, but the negative rate also relaxed after 2011. Zone-4 had a large negative scale from 2011 to 2015. There were two massive typhoons in 2013 and 2014. The natural beach remains in this zone, and the dune behind the beach was severely eroded. This means that dune protection is an important measure to preserve the sand volume in this area. Judging from the change of the volume calculated before and after the beach nourishment, a certain degree of effect by the beach nourishment can be seen in slowing down the rate of the sand volume change. 


\subsection{Longshore sandbar evolution}

Fig. 7 shows the averaged location of the longshore sandbar from 1982 to 2015 in each zone. In case of a single sandbar found along a cross-section, this study defined it as an outer sandbar. If two sandbars are located along a cross-section, this study identified them as an outer sandbar and an inner sandbar.

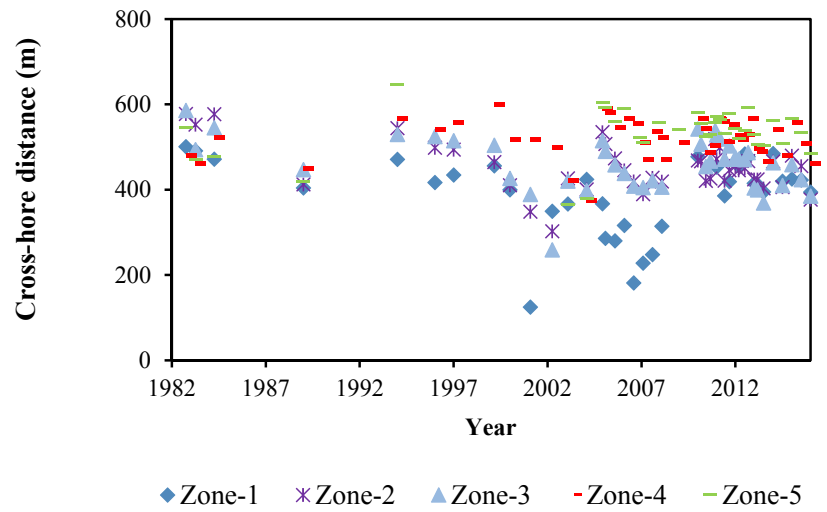

(a)

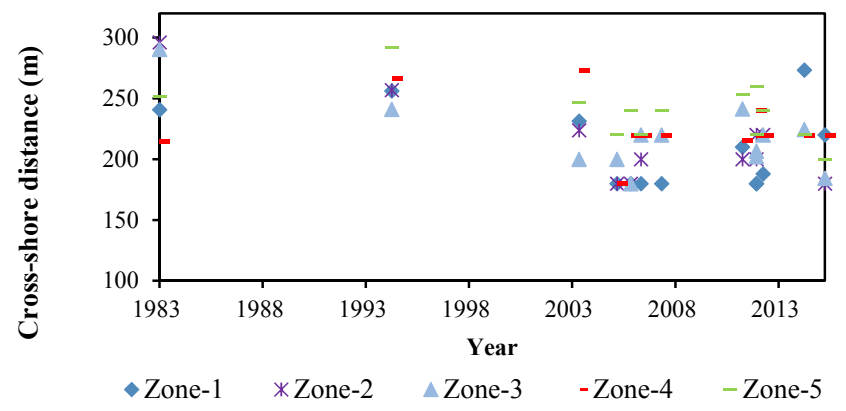

(b)

Fig. 7. Longshore sandbar location in each zone, (a) outer bar crest location, (b) inner bar crest location.

The location of the outer sandbars has fluctuated until the first half of 2000 from 1982. The number of inner sandbars is small in this period. On the other hand, the location of outer sandbars seems stable with the tendency of approaching the landward from the second half of 2000 in all zones. Furthermore, the inner sandbar is frequently found in the zones except for Zone-2. It seems that the beach nourishment boosts the formation of multi sandbar system in this zone.

Fig. 8 shows the change of longshore sandbar height in each zone. The longshore sandbar height was defined as a vertical distance between trough elevation and sandbar crest. The longshore sandbar height fluctuated mostly until the first half of 2000 . From the second half of 2000, the longshore sandbar height in Zone-4 and five show increasing tendency, and the height in Zone-1, Zone-2, and Zone-3 show decreasing one.

Fig. 9 shows the change of the averaged longshore sandbar scale in height and width that is a horizontal distance between longshore sandbar crest and trough. The longshore 
sandbar heights after the beach nourishment in each zone are more significant than the heights before the nourishment. Also, the distance between sandbar crest and trough becomes longer. From the tendency of increasing the longshore sandbar scales, it is inferred that a certain degree of beach nourishment effects on the longshore sandbar evolution.

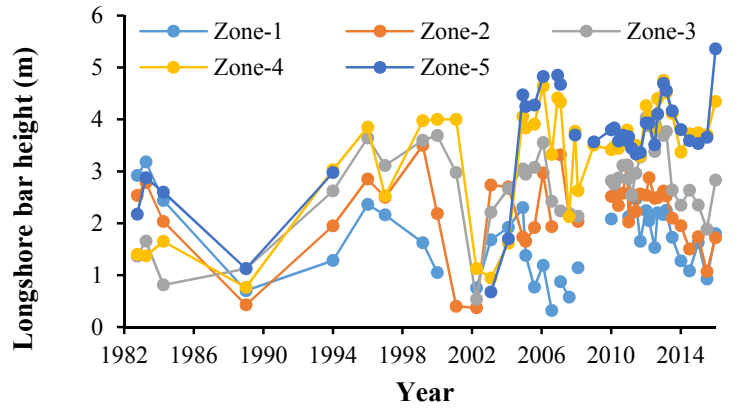

Fig. 8. Longshore sandbar height in each zone.

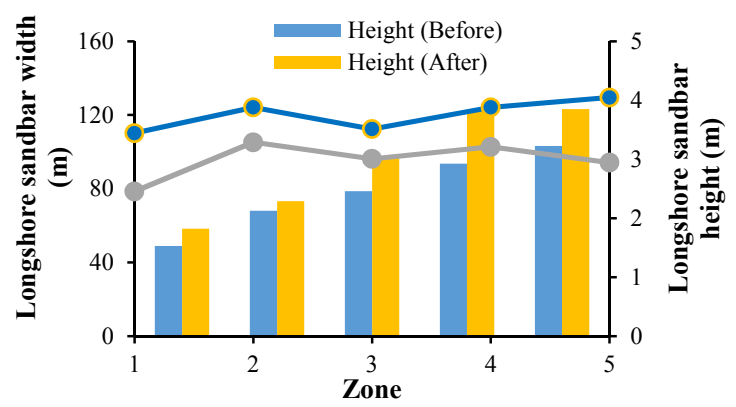

Fig. 9. Averaged sandbar scale in each zone.

\section{Conclusions}

From the results of the sand volume changes before and after the beach nourishment, a certain degree of effect by beach nourishment can be seen in slowing down the rate of the sand volume change, though the sand volume is still insufficient. The outer sandbar exists stably from the second half of 2000 in Miyazaki Coast, and the multi sandbar system seems to be formed. Also, the sandbar scales, such as height and distance between sandbar crest and trough, tend to become larger. It appears that the beach nourishment contributes to the longshore sandbar evolution. The effectiveness of the nourishment can be seen in the Miyazaki Coast, though the degree of effect varies depending on the area, and the nourishment needs to be continued. The longshore sandbar migration could be one of the useful indicators to monitor the effectiveness of the beach nourishment.

This study used bottom sounding data and nourishment sand data measured by Miyazaki Office of Rivers and National highways, Kyushu Regional Development Bureau, Ministry of Land, Infrastructure, and Transport. We appreciate the permission of using those data.

\section{References}

1. T. Uda, Japan's beach erosion -reality and future measures (Sankaido Press, Tokyo, 1997) 
2. H. Tsurusaki, S. Manabe, K. Kikuchi, K. Shimoda, T. Takagi, T. Horiguchi, H. Yagi, S. Sato, Journal of Japan Society of Civil Engineers, Ser. B2 (Coastal Engineering) 68, 2 (2012)

3. S. Elgar, E.L. Gallagher, R.T. Guza, Journal of Geophysical Research 106, C6 (2001)

4. Y. Takano, S. Sato, Journal of Japan Society of Civil Engineers, Ser. B2 (Coastal Engineering) 72, 2 (2016)

5. K. Murakami, S. Sato, R. Nishi, H. Matsuda, Y. Suwa, et al., Journal of Japan Society of Civil Engineers, Ser. B2 (Coastal Engineering) 71, 2 (2015)

6. Sato, J. of Japan Society of Civil Engineers, Ser. B2 (Coastal Engineering) 68, 2 (2012)

7. M. Sugiyama, H. Kadota, T. Horiguchi, H. Yagi, C. Nagata, et al., Journal of Japan Society of Civil Engineers, Ser. B2 (Coastal Engineering) 65, 1 (2009)

8. R. Higashi, S. Sato, Journal of Japan Society of Civil Engineers, Ser. B2 (Coastal Engineering) 72, 2 (2016) 